\title{
La gran estafa de la "producción académica”
}

\section{The great scam of "academic production"}

Ester Caparrós Martín, Diego Martín Alonso, J. Eduardo Sierra Nieto, Manuel Fernández Navas, Noelia Alcaraz Salarirche, Mayka García García, Ana Yara Postigo Fuentes, Laura Pérez Granados, Álvaro Pérez García y Javier Montero González.

Equipo Editorial*

Recibido: 28 de enero de 2022 Aceptado: 28 de enero de 2022 Publicado: 31 de enero de 2022

To cite this article: Caparrós Martín, E., Alonso Martín, D., Sierra Nieto, J., Fernández Navas, M., Alcaraz, N., García García, M., Postigo Fuentes, A., Pérez Granados, L., Pérez García, Á. y Montero González, J. (2022). La gran estafa de la "producción académica". Márgenes, Revista de Educación de la Universidad de Málaga. 3(1), 5-6

DOI: http://dx.doi.org/10.24310/mgnmar.v3i1.14191

\section{RESUMEN}

Editorial de presentación del Volumen 3 número 1 de Márgenes, Revista de Educación de la Universidad de Málaga. Séptimo número de la revista, compuesto por un total de 17 textos, distribuidos en las diferentes secciones. Se trata de un número de carácter ecléctico en el que continuamos ofreciendo contenidos fieles a las premisas y los pilares educativos con los que partíamos.

Palabras clave: producción académica

\section{ABSTRACT}

Editorial presentation of Volume 3 number 1 of Márgenes, Revista de Educación de la Universidad de Málaga. Seventh issue of the journal, consisting of a total of 17 texts, distributed in different sections. This is an eclectic issue in which we continue to offer content faithful to the premises and educational pillars with which we started.

Key word: academic production

Es ya un habitual en nuestro editorial comenzar haciendo alusión a las diferentes cuestiones educativas que abordamos en los números publicados o a las tensiones que vivimos en el mundo de la docencia o en el de la investigación en educación. Y aquí seguimos, caminando por los márgenes con una mirada atenta, reflexiva y crítica, sobre todo porque no queremos quedar marginados de la realidad que vivimos, tanto en la educación en general, como en la investigación en particular. Porque si de algo sirve el cuerpo que da forma a Márgenes. Revista de educación de la Universidad de Málaga es para acoger lo que va dando forma a su alma: las experiencias, investigaciones, estudios y ensayos, trayectorias e historias que van explicitando otros modos de mirar, de pensar, que se resisten a la machacona tendencia de reducir el oficio docente e investigador a la producción des-medida desde la lógica de la meritocracia y al servicio de lo que podemos llamar una "burbuja académica".

Sin más interés que el de ser portavoces de quienes nos hacen llegar sus propuestas y reivindicaciones, no queremos dejar pasar por alto lo que algunos colegas expresan acerca de la necesidad de convertir la evaluación de la actividad investigadora en un modelo basado en la calidad (y no en la cantidad) y que esté al servicio de la ciencia entendida como abierta, gratuita y orientada al interés social. 
Por ello se incluye en este número un manifiesto que nos ha llegado a propósito de la recién estrenada publicación de la convocatoria de sexenios por parte de la ANECA en este año 2022. Nos resulta de interés esta reflexión ya que explicita cómo los investigadores e investigadoras estamos sometidos a la lógica de "publicar o perecer". Y con ello se evidencian los argumentos que expresan cómo dicha lógica de lo que nos habla es de una tarea intercambiable por ránquines y medidas de excelencia, que deja de lado la producción como creación e, incluso, como verdadera transferencia social.

Recordemos que nuestra filosofía, trata de sostener unos modos de investigación educativa que considera los siguientes ejes: (i) que investigar debe aportar intrínseca y extrínsecamente al conocimiento científico; (ii) que quien investiga, se investiga y no puede quedarse al margen de lo que sucede (y le sucede) en dicho proceso; (iii) que la indagación tiene modos de aproximación a la realidad que no pueden ser cosificados en reglas de publicación basadas en técnicas; y (iv) que por supuesto, lo que produce investigar, además de texto e informes, no se puede valorar si lo que prima para evaluación es la cantidad de citas, la posición de la revista en la que se publica y la cantidad de repositorios en los que se aloja.

Consideramos que la difusión científica y la transferencia del conocimiento, fruto de la actividad que desarrollamos tantas y tantos investigadores en el campo de la educación, merece reconocer las trayectorias individuales y personales producidas y recogidas en diferentes textos, narraciones y producciones. Eso alentaría a quienes escriben (y nos escriben) a mantener una producción sensata, reflexiva y sostenible, no consumible sino abierta para ser compartida, que sea libre y gratuita. Esto también fomentaría, entre quienes nos dedicamos a esta actividad, guiar nuestras decisiones de investigación fundamentalmente bajo criterios epistemológicos, metodológicos y ontológicos coherentes; y no a cuestiones de orden competitivo, meritocrático o instrumental. Porque no olvidemos que esa lógica mercantilista —que produce itinerarios de investigación más ligados a la producción "al peso" que a la reflexión y avance social del conocimiento- ya lo viven hasta quienes acuden a la escuela...

Y es que nuestros niños y niñas también son investigadores e investigadoras, si es que los dejamos que aprendan descubriéndose mientras crean y producen libremente. Pero lamentablemente aún nos encontramos con procesos educativos cerrados, que limitan la producción de las criaturas al aprendizaje de contenidos academicistas, que cercan el saber a los currículos basados en libros de texto y fichas cerradas... como le pasa a Gabriel, uno de los protagonistas de la Historia Mínima de nuestra queridísima Mari Carmen Díez Navarro, y que encontraréis en este número. Gabriel es un niño que se encuentra en una escuela donde crear es algo difícil y restringido y que tiene una naturaleza que, por mucho que nos pese, se aleja de la libertad y el crecimiento propio. Por eso, queremos recoger en estas páginas algo que nos parece importante no perder de vista en nuestra tarea docente e investigadora, que producir, como sostiene Mari Carmen es "derramarse, sacar fuera nuestra particular manera de percibir, de recordar, de sentir, mostrar cómo transformamos las vivencias en materiales inéditos, recién nacidos, acabados de crear”. Que producir no puede malentenderse como reproducir (si hablamos del plano escolar), pero mucho menos producir a granel bajo estándares (si hablamos de la investigación).

Deseamos finalizar este editorial rescatando otra de las Historias Mínimas del número, que tiene la firma del maestro, profesor e investigador de la Universidad de Valladolid, Gustavo González-Calvo. Gustavo dedica su relato a recordar (que quiere decir etimológicamente, volver a pasar por el corazón), a José Juan Barba-Martín, a quien perdimos hace ahora seis años. Josito, como lo llama nuestro autor, atesoró una gran carrera como maestro e investigador, y se empeñó en visibilizar la investigación cualitativa en sus trabajos y a través de la creación - hace casi 10 años - de una revista especializada justamente en investigación cualitativa en educación: Qualitative Research in Education ( $Q R E)$; revista que continúa su labor de manera exitosa, de la mano de los editores Aitor Gómez (Universida Rovira i Virgili) y Raúl A. Barba-Martín (Universidad de León). Desde Márgenes no podíamos sino acoger este texto y sumarnos a este reconocimiento que nos propuso Gustavo, a través de esta Historia Mínima in memoriam.

Dejamos como siempre la puerta entreabierta y las lecturas sobre la mesa, y os invitamos a encontrarnos en los Márgenes. 